\title{
O transcinema de Lúcia Murat. Memórias dos anos 70 por meio da imersão e da coautoria com o espectador
}

\author{
Denise Costa Lopes \\ Pontifícia Universidade Católica do Rio de Janeiro (PUC-Rio), Brasil
}

\section{Abstract}

A long trip (2012), by Lúcia Murat, turns the screen into a postcard, video art, live cinema, installation, photo album, letter, map ... It works as a register of an era as 'transcinema'. The film mixes past and present, reality and fiction, to recount the steps of Heitor, the filmmaker's brother, who was sent abroad in 1969 by the family in fear that he would follow Lúcia's footsteps in the armed struggle. It's updates the cinematographic devices and turns the viewer into a co-author. Filled with hybrids, it enlarges the possibilities of the 'cinema form', expanding it. Digital features allow for a strong 'between-the-images', uniting projections of differents supports, temporalities, spatialities and cultures.

The nine years when Lúcia and Heitor were apart _ when he took two trips around the world, while she was trying to survive under the oppression of the military regime _ function also as a way to highlights the memories of an obscure period in Brazil. It creates a paradoxical and synaesthetic immersion at the 70's, where "getting lost seemed to be the only way to find oneself". Under the effect of an 'endless eye', it generates a powerful 'trompe l'oeil' that broadens horizons. 'Infinite lucarne' lead the viewer to fill in the gaps in a psychedelic kaleidoscope and to experience the film as an observer who atones for this generation's deeds. The goal of this work is to analyze these constructions and identify how this language helps promote immersion in the film, which works with memory.

Keywords: Synaesthetic Immersion, Co-authorship, Transcinema, Lúcia Murat, Memory

\section{Introdução}

Três jovens irmãos cheios de ideais apartados. Um governo de exceção, uma ditadura militar, assassinatos, torturas, prisões, repressões, desmandos. Uma luta armada, assaltos a bancos, sequestros de embaixadores, clandestinidades, acertos e enganos. Uma revolução cultural ressoando, Woodstock, novos anseios de liberdade, beatniks, On the roads, hippies, contracultura, drogas leves e pesadas, buscas pelo Nirvana, retornos ao mítico e ao puro, guerra no Vietnam e muita repressão aos movimentos revolucionários. Uma imersão sinestésica e psicodélica na confluência dos 70. Assim é Uma longa viagem, filme de 2012 de Lúcia Murat.

Cineasta brasileira mulher com o maior número de longas realizados, Lúcia fez da tela carta, cartãopostal, videoarte, cinema ao vivo, instalação, álbum fotográfico, mapa... Teceu um registro pictórico, fotográfico e fílmico de uma época, em que "se perder parecia ser o único meio de se encontrar", construindo o que poderíamos nomear hoje como um transcinema (Kátia Maciel). Repleto de hibridações, o longa amplia novas possibilidades da "forma cinema" (André Parente), solidificada comercialmente no último século, expandindo-a (Gene Youngblood). Ao misturar passado e presente, realidade e ficção, para contar os passos de seu irmão mais novo, Heitor, enviado, em 1969, para o exterior pela família temerosa de que ele viesse seguir os passos da cineasta engajada na luta armada, o filme atualiza o dispositivo cinematográfico e transforma o espectador num coautor.

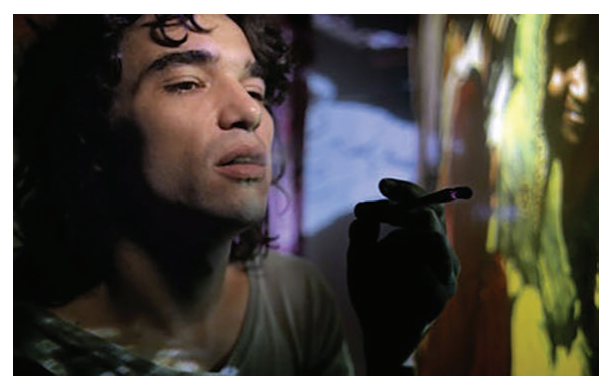

Figura 1 - Caio Blat como Heitor em Uma longa viagem. Disponível em: http://www.taigafilmes.com/longaviagem/. Acesso: 20/05/19.

\section{Coautoria por meio da imersão}

Como um viajante a espiar e expiar também de forma potente a travessia recente da geração dos anos 70, o espectador percebe o universo recriado pela memória de Lúcia e Heitor, protagonista do filme, plasmado nas imagens que passam no filme dentro do filme. Numa tela fictícia localizada por detrás dos monólogos de Heitor, representado pelo ator Caio Blat, o espectador vai vivenciado as imagens reais ou não da travessia dos dois irmãos por aqueles conturbados anos. Imersos, assim, em "claraboias infinitas" (Noël Burch), o espectador vai tecendo a teia do filme e misturando suas próprias memórias construídas sobre o período em questão. O filme dentro do filme denuncia a construção imagética, a realidade que é inventada pelo cinema (Jean Mitry), e torna a fruição cinematográfica imersiva e potente. Por meio de lacunas temporais, espaciais, de significados e sentidos, Uma longa viagem atira o espectador num turbilhão vertiginoso de emoções e conflitos geracionais. Analisar essas construções e identificar como essa linguagem ajuda a promover a imersão do espectador na obra é um dos objetivos desse trabalho.

Ao trabalhar sobretudo com a memória dos anos 70 , a partir do relato da história real de seu irmão, 
que atravessou o mundo duas vezes naquela década, Lúcia constrói o retrato de toda uma geração, espremida entre o desejo de liberdade e a opressão das revoluções políticas, culturais e de costumes do pós-anos 60. Essa dicotomia entre liberalidades e repressão é expressa no filme a partir da própria trajetória dos dois irmãos. Pois enquanto Heitor viajava pelo mundo movido pelos ideais beatniks, usando drogas, vivendo como um hippie nômade ou preso por tráfico de drogas por breves períodos, Lúcia vivia escondida em aparelhos no Brasil, sendo presa e torturada pelo regime de exceção ou cumprindo pena de cinco anos numa penitenciária no Rio de Janeiro. Os nove anos em que os dois estiveram separados serve de pano de fundo para Lúcia revirar suas memórias pelo avesso e realizar uma reflexão acerca de suas escolhas pessoais e de seu irmão.

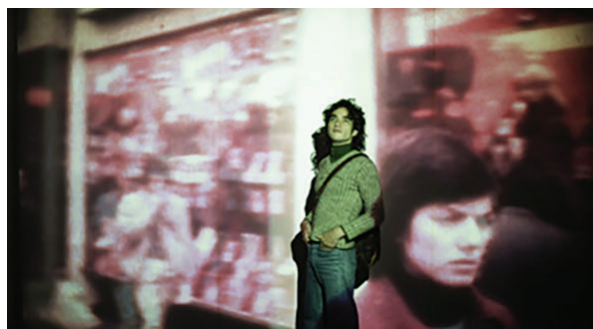

Figura 2 - Filmes dentro do filme. Imagens de ontem e de hoje plasmadas. Disponível em: http://www.taigafilmes.com/ longaviagem/. Acesso em: 20/05/19.

\section{Obra de tom documental com viés ficcional}

O longa, que opta pelo tom documental com viés ficcional, como muitos filmes de Lúcia, mistura passado e presente, realidade e ficção, atualizando o dispositivo cinematográfico. Depois de duas voltas pelo mundo, consumindo drogas e vivendo como os hippies, Heitor acaba por desenvolver um grau de dissociação das ações e do pensamento, que o tira muitas vezes da realidade circundante. Preso por tráfico de drogas na Holanda, foi resgatado pela família de uma internação na Embaixada americana na Índia, em 1978. As inúmeras cartas e cartões postais trocadas com a família nos quase dez anos de autoexílio serão a base do relato textual do filme, que mescla fatos pessoais e acontecimentos políticos. No site do longa, a diretora parece assumir o risco:

Talvez o fato de vivermos um tempo em que muitas certezas foram colocadas em xeque, que utopias caíram em desuso, nos leve a querer abordar os fatos de outra maneira, a partir de experiências pessoais. O pessoal e o político tratados de uma forma mesclada, quem sabe pode abrir novos caminhos, mais livres.

(MURAT, http://www.taigafilmes.com/longaviagem/. Acesso em 13/04/19)

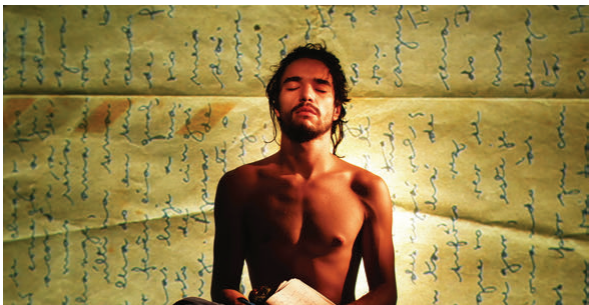

Figura 3 - Cartas, cartões postais, bilhetes guiam a narrativa do passado. Disponível em: http://www.taigafilmes.com/ longaviagem/. Acesso em: 20/05/19.

\section{Caleidoscópio psicodélico ‘entre-imagens'}

Por meio de recursos digitais, que permitem um vigoroso "entre-imagens" (Raymond Bellour), Uma longa viagem une projeções de suportes distintos (super-8, $35 \mathrm{~mm}$, digital, fotográfico, etc), temporalidades, espacialidades e culturas diversas, como do Brasil, Afeganistão, Tailândia, Ilha de Páscoa, Nova Zelândia, Índia, entre outros. Monta num caleidoscópio afetivo e sob efeito de um "olho interminável" (Jacques Aumont), um vigoroso trompe l'oeil, que amplia tela e horizontes.

Para criar uma ambiência catártica e livre, Lúcia expõe na tela, como numa parede de museu, muitas referências à pintura, ao cinema, às artes em geral. Da analogia ao lisérgico Apocalypse Now (Francis Ford Coppola, 1979) às performances do poeta Chacal em Londres, gravadas por Luciano Figueiredo, no princípio da videoarte no Brasil das décadas de 1960 e 1970, o filme assume uma estética psicodélica própria dos 70 . Caio Blat, ator que refaz, em monólogos, as memórias de Heitor, irmão mais novo de Lúcia, se funde, se sobrepõe, se foca e se desfoca por sobre as imagens do passado, num cenário feito basicamente de luz.

Plasmado esteticamente, como fio condutor, às lembranças afetivas, muitas vezes confessadamente forjadas, Caio/Heitor contracena com a imagem em movimento de Heitor. Separados no tempo e no espaço pelo relato de Heitor na correspondência enviada à família na época de suas viagens e pela narração atual do mesmo Heitor mais velho, capturado pela câmera de Lúcia, Caio/Heitor e Heitor se encontram algumas vezes em cena sem nunca de fato terem sido filmados juntos. Caio contracena com a cena filmada de Heitor, enquanto Heitor rememora um trecho de suas passagens praticamente da mesma forma como a descreveu por carta. A literalidade idêntica da palavra escrita e falada une os dois. Os braços de Caio e de Heitor percorrem o mesmo arco no ar. Suas bocas emitem as mesmas sequências verbais. Seus olhos transparecem o mesmo brilho, com a mesma paixão pelo relato. Por ora, esquecemos que são dois. Realidade e ficção coalhadas na mesma tela, em total contaminação, onde já não conseguimos diferenciar uma da outra. Onde é documentário? Onde é ficção? Tênues fronteiras que parecem não importar mais. Pois como Jean Mitry e outros fizeram questão de pontuar há tempos, "uma realidade filmada no cinema é sobretudo uma realidade de cinema". 


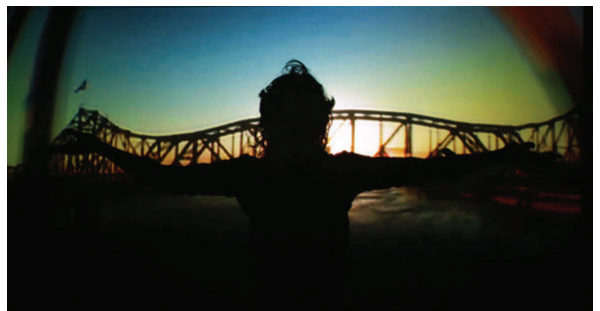

Figura 6 - Caio/Heitor interage com as memórias dos 70 . Disponível em: http://www.taigafilmes.com/longaviagem/. Acesso em: 20/05/19.

Embora centrado nas memória da diretora e de seu irmão caçula, foi a morte do irmão mais velho de Lúcia que a levou a desejar realizar Uma longa viagem. O médico Miguel Murat Vasconcellos (nome também do pai de Lúcia e não por acaso de um dos personagens principais de seu filme Quase dois irmãos), chefe do Departamento de Administração e Planejamento em Saúde da Fundação Oswaldo Cruz (Fiocruz) e pesquisador da Escola Nacional de Saúde Pública Sergio Arouca, se dedicou às pesquisas e práticas médicas que podiam alavancar melhorias sociais no Brasil. Terceiro vértice das vivências possíveis em prol da liberdade e das causas revolucionárias da década de 70 . O cruzamento do caminhos dos três irmãos, membros de uma família de classe média brasileira, funciona como um espelho geracional destes convulsionados anos.

\section{Memória dos erros e acertos do pós-golpe de 64}

Uma longa viagem faz parte de um grupo de quatro filmes que parecem investigar os erros e acertos da geração de Lúcia durante a ditadura no Brasil. Junto a Quase dois irmãos (2004), A memória que me contam (2012) e Que bom e ver viva (1989) dá vida à expressão mais importante de sua obra. São olhares corajosos para um passado recente e doloroso, autobiográficos em diferentes graduações, catárticos, aglutinadores, pessoais e, talvez, sobretudo exatamente por isso, universais na produção de sentidos, como toda potente obra de Lúcia.

Em Quase dois irmãos, narra o encontro de dois meninos, um do asfalto, outro do morro, 30 anos depois, dentro do Presídio da Ilha Grande. A partir dessa relação, Lúcia vai, não só refletir sobre a dificuldade dessa interação social numa cidade partida, como também sobre até que ponto o convívio, nessas penitenciárias, entre presos comuns, em sua maioria assaltantes de bancos, e presos políticos, não foi responsável pela conscientização sobre a importância de estruturação de coletivos com estratégias de luta e de poder de guerrilha dentro do cárcere. Teorias afirmam que as práticas dos presos políticos nesses presídios influenciaram a criação de organizações como o do Comando Vermelho e da Falange Vermelha, que acabaram por controlar o tráfico de drogas no Rio de dentro do sistema penal. Claudio Torres da Silva, namorado de Lúcia na época, que havia participado do sequestro do embaixador americano Charle Burke Elbrick, em 1969, e que só ganhou liberdade em 1976, foi um dos presos políticos, por exemplo, que passaram pela ilha e testemunharam a gênesis dessas organizações criminosas.

Ousado na abordagem, Quase dois irmãos talvez seja o filme mais completo e premiado de Lúcia. Ganhou melhor filme ibero-americano em Mar del Plata, especial do júri no Huelva Latin American Film Festival, melhor direção na Première Brasil e melhor filme latino-americano da Federação Internacional de Críticos de Cinema (Fipresci) no Festival Rio, de roteiro da antiga Associação de Críticos de São Paulo, além de prêmios de público, no Brasil e no exterior. Com roteiro de Lúcia e Paulo Lins, autor de Cidade de Deus (1997), foi selecionado para o Laboratório do Sundance e conseguiu aportes do Ministério das Relações Exteriores da França, através do Fonds Sud Cinéma.

Já A memória que me contam, inspirado na vida da militante, economista e socióloga Vera Sílvia Magalhães, uma das responsáveis pelo sequestro do embaixador norte-americano, Lúcia fala sobre conflitos com filhos, "utopias derrotadas, terrorismo, comportamento sexual e construção de um mito", e lança mão de boa dose de metalinguagem para poder construir um filme dentro de um filme de forma poética e misteriosa em tom de homenagem à sua grande amiga. Referência da luta armada do antigo MR-8, com participação em assalto a bancos, supermercados, postos de gasolina, carrosforte e ao apartamento do deputado Edgar Guimarães de Almeida, em Copacabana, Vera foi baleada na cabeça e presa em 1970. Barbaramente torturada, foi trocada junto com outros 39 presos políticos pelo embaixador alemão Ehrenfried von Holleben, sequestrado no mesmo ano. Embora fosse projeto antigo, foi a morte de Vera, em 2007, a prisão de Cesare Battisti, ex-membro da luta armada na Itália, com ameaça de extradição, e a criação da Comissão da Verdade, que começou a revelar os violentos atos contra os direitos humanos praticados pela ditadura militar, que deflagraram a necessidade do filme, segundo Lúcia.

\section{Estreia no boom do cinema de mulher no Brasil}

É nessa dimensão também que Uma longa viagem se assemelha a Que bom te ver viva, primeiro filme de Lúcia a estrear no Brasil. Quando Que bom te ver viva (1989) estreou, poucas eram ainda as cineastas de expressão no Brasil, e muitas, como Suzana Amaral ( $A$ hora da estrela/1986), Tizuca Yamasaki (Gaijin, 1980, e Parayba, mulher macho/1983) e Ana Carolina, com sua emblemática trilogia sobre as pulsões do universo feminino (Mar de rosas/1978, Das tripas, coração/1982, e Sonho de valsa/1987), se lançavam nessa aventura exatamente por essa época. Ver na tela a força do testemunho de uma personagem central (Irene Ravache), alter ego da diretora do filme construído ficcionalmente, misturado a relatos reais de outras exmilitantes e guerrilheiras, passando a limpo as bárbaras torturas físicas e psicológicas sofridas nos porões da ditadura, foi um choque visceral na cinematografia 
brasileira. Muito mais voltada, desde meados da década de 70 , à exibição exaustiva de mulheres em situações afetivas sadomasoquistas, obsessivas e de desmérito em tramas eróticas e pornochanchadas explícitas, o corpo da mulher aparecia ali totalmente dilacerado pela opressão de um governo de exceção, carregando a discussão para muito além das perversões cotidianas do repertório machista e patriarcal nacional. Vale lembrar que ali ainda eram os anos 80 , que havia nos chegado na esteira de A dama do lotação (1978, Neville de Almeida), Calígula (1979, Tinto Brass), Império dos sentidos (1976, Nagisa Oshima, liberado só em 1980 no Brasil) e de toda sorte de facilidades à obscenidade sexual oferecidas pelas recém-criadas locadoras de vídeo no país. A frase título desse primeiro longa-metragem da ex-jornalista Lúcia Murat não fazia ainda muito sentido para uma geração que desconhecia ou conhecia muito pouco das atrocidades da repressão política pós-Ato Institucional $n^{\circ}$ 5 (Al-5) e que se preparava para as primeiras eleições diretas para a Presidência da República, depois de 25 anos de regime militar.

\section{Filmar como forma de resistir}

Será nesse contexto que o nome da ex-militante da Dissidência Estudantil da Guanabara, fruto de uma cisão do PCB, que desembocaria no Movimento Revolucionário 8 de Outubro, MR-8, começou a ser associado ao cinema. Presa, pela primeira vez, aos 18 anos, na queda do Congresso da União dos Estudantes (UNE), em Ibiúna, São Paulo, em 1968, quando cerca de mil universitários foram levados para interrogatórios, e detida de novo pela repressão depois de dois anos e meio na clandestinidade, em março de 1971, com passagens pelo DOI-Codi da Rua Barão de Mesquita, Vila Militar e pelo Presídio Talavera Bruce, em Bangu, onde ficou por três anos e meio até junho de 1974, Lúcia surge na tela grande revirando agruras de um passado ainda muito recente e se utilizando de uma linguagem ousada, que misturava ficção e documentário de forma sutil e irreverente.

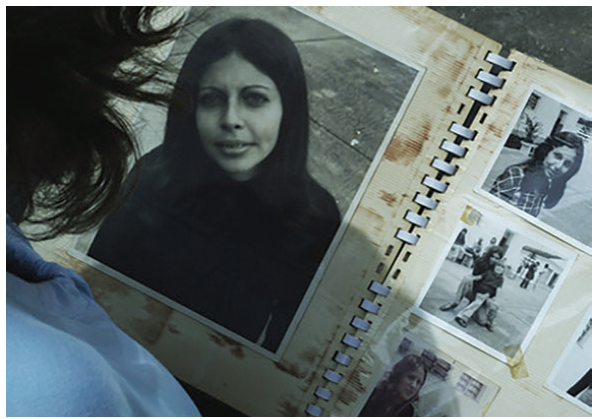

Figura 5 - Albúns de fotos da família mostram os diferentes momentos dos irmãos. Disponível em: http://www.taigafilmes. com/longaviagem/. Acesso em: 20/05/19.

O desfazer da tênue fronteira entre os formatos fílmicos, percorrido já no seu primeiro longa-metragem; a reconstrução de importantes memórias vividas pelos jovens da classe média alta da Zona Sul carioca, que como ela, estudante de Economia e de ballet clássico, se engajaram na luta contra o não estado de direito instaurado no Brasil; a perseguição de um ideal de cinema que beira quase sempre o tom de um filme-ensaio; a desconstrução narrativa muitas vezes associada a livres construções das artes plásticas e da dança; e o viés político, quase sempre autobiográfico, são algumas das marcas da arte de Lúcia.

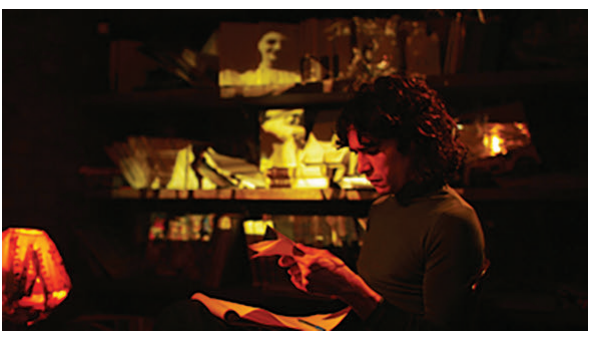

Figura 4 - Imagens por detrás das cenas causam efeito de backprojections. Disponível em: http://www.taigafilmes.com/ longaviagem/. Acesso em: 20/05/19.

Da sua vivência nas redações do Jornal do Brasil, Opinião, TV Globo e TV Manchete, logo depois de sair da prisão, surgiu Doces Poderes (1997), filme que discutiu de forma muito precoce temas atualíssimos, como "a monetarização das relações humanas, o novo papel da mídia, e a crise da ética", a partir da cobertura e das escolhas de jornalistas em meio às eleições dentro e fora das redações. Ao apresentar as discussões sobre o filme no site da sua produtora Taiga Filmes, Lúcia não poderia ser mais profética em relação ao momento que o Brasil vive hoje, em 2019:

Vivemos num mundo onde a razão cínica não se contrapõe mais à razão utópica. O filme Doces Poderes coloca a olho nu esta questão, de vários pontos de vista: o da mídia, o do poder político e o da ótica individual dos profissionais de comunicação. Sua importância está em mostrar como esta questão se dá concretamente no Brasil, um país onde uma democracia recente convive com um capitalismo perverso. Desnudar a forma como o poder político se estabelece, mostrando todas as forças em jogo numa eleição é de extrema importância para que se possa aprender o país que vivemos. As altas verbas destinadas às campanhas eleitorais tornaram natural que publicitários, redatores, repórteres, cinegrafistas e diretores aderissem a esse mercado sem que houvesse qualquer critério, a ão ser o financeiro, para a escolha dos candidatos aos quais iriam servir enquanto profissionais. Premidos na luta pela sobrevivência, perdidos entre os sonhos que acabaram, a questão ética parece ter se tornado algo do passado. A esquizofrenia e a selvageria destas redações estão à mostra neste filme. (...) Poderes poderes ou doces poderes? (...) o filme pergunta como sobreviver a todas estas contradições, se não existe mais um mito no fim do túnel? (MURAT, http://taigafilmes.com/wp/pt/filmes-realizados/docespoderes. Acesso em 14/04/19. 


\section{Do ballet à revolução sandinista}

Do seu amor ao ballet, interrompido pela militância política na juventude, nasceram pelo menos dois filmes: Maré, Nossa história de amor (2007) e Em três atos (2015). No primeiro, o desafio máximo de fazer um musical a la West side story (1961), de Robert Wise e Jerome Robbins, numa das maiores e mais violentas favelas do Rio, exercitando uma cinematografia praticamente sem experiência prévia de peso ou representantes destacados do gênero no país. No segundo, um mergulho vigoroso e delicado na transformação de corpos e mentes femininos com a passagem do tempo na dança e fora dela, marcado pelo trabalho da emblemática Angel Vianna, pelos textos da revolucionária Simone de Beauvoir _ $A$ velhice e Uma morte muito doce, sobre o falecimento de sua mãe e pelo espetáculo Qualquer coisa a gente muda (2011), realizado por João Saldanha, com Maria Alice Poppe, coreógrafo e bailarina, que também estão no filme, assinando, respectivamente, os passos e a contracena com a homenageada Angel.

Com 11 longas-metragens no currículo, um média-metragem, e a participação em um filme de episódios, Oswaldianas (1992), sobre obras de Oswald de Andrade, com o segmento Daisy das almas desse mundo, Lúcia é hoje a cineasta brasileira com o maior número de longas realizados para a tela grande. Em quase todos, assinou direção, roteiro e produção, e antes mesmo de Que bom te ver viva, já havia criado a Taiga, Filmes e Vídeo para realizar com seu companheiro na época, Paulo Adario, hoje diretor do Greenpeace no Brasil, e que viria a ser pai da sua filha também cineasta, Júlia Murat, $O$ Pequeno Exército Louco (1984), um média-metragem filmado na Nicarágua, entre 1978 e 1979, sobre a Revolução Sandinista e a presença norte-americana no país desde os anos 30. O tema político e a ponte com o exterior, presentes já nesse seu primeiro trabalho audiovisual, nunca saíram da pauta da sua produtora, que vem se dedicando cada vez mais em promover coproduções internacionais, em especial com a França, país do qual ganhou em maio de 2013 a medalha Chevalier des Arts et Lettres em reconhecimento à sua contribuição à cultura das duas nacionalidades e a uma maior aproximação entre estas.

\section{Olhar estrangeiro}

Foi, aliás, a partir de um "olhar estrangeiro", não à toa título de outro longa seu, que Lúcia realizou dois filmes sobre um mundo pouco conhecido pelo homem branco brasileiro: o dos índios do país. E tanto Brava gente brasileira (2000), uma ficção baseada numa história verídica de resistência dos índios guaicurus, que, em 1778, enfrentaram os colonizadores portugueses no Forte Coimbra no Pantanal do Mato Grosso do Sul, quanto $A$ nação que não esperou por Deus (2015), documentário que dirigiu com Rodrigo Hinrichsen, seu assistente em Brava gente..., sobre a forma de vida e a luta pela demarcação das terras dos kadiwéus, descendentes dos guaicurus, que também atuaram 15 anos antes na ficção histórica com nome tirado do verso de Evaristo da Veiga para o Hino da Independência, tiveram financiamentos de programas, coproduções e distribuições internacionais.

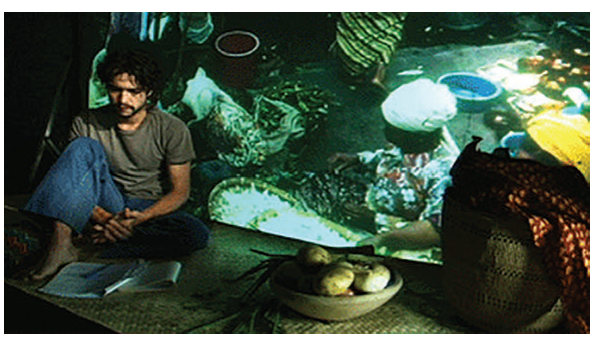

Figura 7 - Heitor (Caio Blat) plasmado às suas memórias de forma literal por meio das projeções no cenário. Disponível em: http://www.taigafilmes.com/longaviagem/. Acesso em: 20/05/19.

Em Olhar estrangeiro (2005), baseado na vigorosa pesquisa do livro $O$ Brasil dos gringos: imagens no cinema (Intertexto, 2000), de Tunico Amancio, Lúcia discute o próprio poder da sétima arte, dialogando com produções de fora, que tiveram o Brasil como tema ou pano de fundo para suas tramas, a fim de desvendar a origem dos inúmeros erros, clichês e fantasias que existem sobre o Brasil no exterior, e que se refletem na visão que o próprio cinema mundial expressa sobre o país. A lista de filmes citados, que cria exóticos fetiches, na maioria inverídicos, sobre o Brasil e os brasileiros, é grande. Vai de Wild Orchid (EUA, 1990), de Zalman King, a superproduções, como The burning season (Amazônia em chamas, EUA, 1994), de John Frankenheimer, produções independentes, como Next stop, Wonderland (EUA, 1999), de Brad Anderson, e obras mais antigas, como L'homme de Rio (FRA, 1964), de Philipe de Brocca. Sem fechar teses ou perseguir raciocínios fáceis, Lúcia ouviu diretores, produtores, roteiristas, atores, e toda sorte de interlocutores vivos destas produções na França (Lyon e Paris), Suécia (Estocolmo) e EUA (Nova York e Los Angeles). Michael Caine (Blame it on Rio, EUA, 1984, de Stanley Donen), Jon Voight (The champ, EUA, 1979, de Franco Zeffirelli, e Anaconda, EUA, 1997, de Luis Llosa), e David Weisman, produtor de O beijo da mulher aranha (1985), de Hector Babenco, foram alguns dos indagados sobre possíveis senões e inverossimilhanças acerca da cultura e do caráter brasileiro projetados na tela. Algumas entrevistas traduziram grandes desinformações e pré-conceitos que, somados à necessidade de reforçar estereótipos e construir ficções que beirassem o inusitado, justificaram o ideal bastante distante e forçado construído sobre nós, que nos deforma e forma no exterior.

\section{Os últimos trabalhos}

Seu mais recente longa, Praça Paris, que Ihe conferiu melhor direção no Festival do Rio de 2017, e melhor atriz para Grace Passô, carrega nas cores sociais, mas foge um pouco da sua trajetória marcada 
fortemente por um viés mais pessoal. Numa situação quase de triller, Praça Paris traz para a cena o momento atual do país e, em especial, do Rio de Janeiro, que vive uma crise institucional e econômica sem precedentes nos últimos anos. O impasse vivido com a penúria e o quase fechamento da Universidade Estadual do Rio de Janeiro (UERJ), a primeira no estado a adotar o sistema de cotas para ingresso, e a evidente falência da segurança pública em solo fluminense ganham destaque na trama. Fora isso, Lúcia acaba de lançar Vestígios do Brasil, uma série documental em 12 episódios que revela a história da expansão territorial brasileira do século $X X$ através da tomada dos territórios indígenas.

\section{Conclusão}

Toda a obra de Lúcia ressoa o público e o privado. Mas talvez tenha sido em Uma longa viagem que a diretora tenha ido mais longe nessa exposição pessoal de difícil equação. Ao reconstruir sua história e do desencontro com seus irmãos de forma visceralmente autoral, Lúcia visitou de forma intensa e próxima suas próprias entranhas e desenlaces familiares surgidos de um passado político recente e doloroso. Expôs, não só a rememoração de três jovens irmãos que se amavam e que passaram quase dez anos sem poder se encontrar, mas a memória de toda uma geração, que, pelo menos no Brasil, foi cerceada e impelida a se sentir estrangeira dentro e fora do país. Afinal, as histórias de Lúcia, que ficou boa parte desse tempo presa em Bangu, de Heitor, que viajava pelo mundo, e de Miguel, o irmão médico, elo dos dois, que abraçou as causas libertárias e sociais por meio do trabalho, são o retrato de um Brasil dilacerado por força das circunstâncias políticas de seu tempo. Espelhos de inúmeros outros jovens contemporâneos a eles.

O impedimento do encontro dos três de novo, cerca de 30 anos depois, pela morte prematura de Miguel, que levará Lúcia a repensar a relação do trio, e os impedimentos de convivência engendrados entre eles criam uma dimensão reflexiva que vai muito além do momento passado. Produz um olhar, autobiográfico em diferentes gradações, catártico, aglutinador, extremamente pessoal e, talvez, sobretudo por isso, universal na produção de sentidos.

A estética adotada nessa longa viagem, que lembra a de uma instalação videoartística, carrega seus espectadores para dentro dos acontecimentos que narra de forma sensorial, dividindo com esse a tarefa de autoria. A viagem aos 70 , orquestrada por Lúcia, nos tira de uma zona de conforto e nos faz refletir sobre os rumos de uma geração que promoveu mudanças comportamentais, políticas, sociais e culturais radicais, mas que acabou, de alguma forma, assistindo a esses ideais serem sufocados ou se arrefecerem. Ao olhar para o passado, Uma longa viagem, mesmo em 2012 quando foi lançado, nos fazia refletir também sobre o futuro. Tão ou mais precário e incerto do que esse período de exceção da história recente brasileira que narra.

\section{Referências bibliográficas}

AUMONT, Jacques. 2004. O olho interminável. São Paulo: Cosac Naify.

BELLOUR, Raymond. 1997. Entre imagens. Campinas: Papirus.

BURCH, Noël. 2007. La lucarne de l'infini. Naissance du langage cinématographique. Paris: L'Harmattan.

MACIEL, Kátia (Org.). 2009. Transcinemas. Rio de Janeiro: ContraCapa.

MITRY, Jean. 1989. Estética y Psicología del cine. Las estruturas. Madrid: Siglo XXI, vol.2.

MURAT, Lúcia. Site da Produtora TaigaFilmes. Disponível em: http://taigafilmes.com/wp/pt/home-page/. Acessado em 20/05/19.

PARENTE, André. 2009. A forma cinema: variações e rupturas In: MACIEL, Kátia (Org.). Transcinemas. Rio de Janeiro: ContraCapa.

YOUNGBLOOD, Gene. 1970. Expanded cinema. New York: Dutton.

\section{Filmografia de Lúcia Murat}

Praça Paris. (2017)

Em três atos. (2015)

A nação que não esperou por Deus. (2015)

A memória que me contam. (2012)

Uma longa viagem. (2011)

Maré, nossa história de amor. (2007)

Olhar estrangeiro. (2005)

Quase dois irmãos. (2004)

Brava gente brasileira. (2000)

Doces poderes. (1997)

Oswaldianas. (1992, episódio Daisy das almas deste mundo)

Que bom te ver viva. (1989)

O pequeno exército louco. (1984) 